\title{
Environmental Aspects of Treatment with Lactose-containing Biological Preparations in Organic Agriculture
}

\section{E V Pashkova, J A Bezgina, A N Shipulya, L V Maznitsyna, and L A Mikhno}

Department of Chemistry and Plant Protection, Stavropol State Agricultural University, Stavropol, Russia

\section{Abstract}

The paper presents data from developing a technology for production of protectingstimulating lactose-containing biological preparations to be applied in growing small grain crops. The process diagram of the biological preparation production includes 7 stages: raw feed acceptance, quality evaluation; separation of fat and casein dust; production of plant extracts; fermentation of the plant extracts with whey; sterilization; bottling and packaging; storage and sales Studies of qualitative and quantitative indicators of the biological preparation have been completed and its photometric

Corresponding Author:

E V Pashkova

plush.al@yandex.ru

Received: 25 October 2019

Accepted: 15 November 2019

Published: 25 November 2019

Publishing services provided by Knowledge E

(c) E V Pashkova et al. This article is distributed under the terms of the Creative Commons Attribution License, which permits unrestricted use and redistribution provided that the original author and source are credited.

Selection and Peer-review under the responsibility of the AgroSMART 2019 Conference Committee. indicators have been studied to standardize the preparation. Influence of the biological preparation onto growth-stimulating activity of winter wheat seeds variety DON-85 was studied in the laboratory. Application of the protecting-stimulating biological preparation to wheat cultivation (var. DON-95) and agricultural applicability were studied in field studies conducted on the test plots of instructional and experimental farm of Stavropol State Agricultural University. Practical recommendations for use have been developed.

Keywords: organic agriculture, biological preparations, whey

\section{Introduction}

The current problem of conserving the environment for future generations put forward a problem of finding alternative ways of agricultural industry development in different countries of the world [5, 12, 15]. In 2018, the President of the Russian Federation signed a law aimed at establishing conditions for development of organic agriculture with the aim of providing the domestic market with Russian green-labeled produce. 
Organic agriculture (environmentally-friendly farming, biodynamic agriculture) is a form of agriculture that consciously minimizes application of synthetic fertilizers, pesticides, plant growth regulators, feed additives, genetically-modified organisms. In contrast, fertilizers of organic origin and natural protecting-stimulating biological preparations are exclusively used to increase fertility of soils, provide crops with nutrients necessary for plant growth and development and to increase yields [1--3, 9--11].

By now, certain experience has been accumulated in application of bio-sourced preparations for organic agricultural production of high-quality grain $[6,13,14]$. Still acute problems are finding new raw material resources and development of protectingstimulating poly-functional biological preparations that provide increased efficiency of agricultural technologies, production of environmentally-friendly produce and have a positive effect over ecological systems.

When creating a natural biological preparation technology, it is important to seek for economically and environmentally rational resource bases that contain a complex of biologically active substances.

Whey may be one of such raw material resources. Experiments have proven that whey contains the essential complex of biologically active compounds, macro- and microelements; they point to a possibility of its use as a raw material in manufacture of biological preparations aimed at grain production $[7,8]$.

The positive effect from using whey-based bio-preparations in organic farming is largely based upon controlling soil biota by means of directed regulation of microorganismic activity in the soil.

This is related to the following factors:

- the complex of biologically active substances of whey serve as a stimulant of rhizospheric and soil microbial flora, whose activity is essential for most of favorable processes taking place in the soil;

- increased count of stimulating microorganisms in plant's rhizosphere allows increasing fertilizer's A value. The share of microorganisms capable of synthesizing exogenic biologically active substances in the phizosphere increases; these substances activate root nutrition and metabolism, thus providing increased yield and quality;

- biological activity of soil is increased, thus reducing soil exhaustion that is typical when the crop rotation is saturated with crops leaving behind plant residues, which are hard-to-mobilize for microbial flora; 
- favorable soil regimes are created that provide enhancement processes antagonizing phytopatogenic fungi, thus facilitating reduction in amount of applied chemical plant protectors.

Whey includes a complex of bioantioxidants (amino acids, vitamins) that may stabilize the process of lipid peroxidation, increase stress resistance of crops under the influence of unfavorable environmental factors.

When seeds germinate, in parallel with consumption of available vitamins, there is also intensive vitamin production. Increased synthesis of vitamins during this period is determined by physiological demands of the seed. Most of the vitamins are coenzymes of various enzymes and growth regulators that directly participate in the metabolic and growth processes. As a result of vitamin transfer from some parts to others, favorable conditions are created for normal formation of a sprout. During the first hours of seed germination, vitamin PP reacts with other substances, forming NAD and NADPH co-enzymes, which are active groups of multiple enzymes that catalyze about 80 different biochemical reactions. With their help, electrons and hydrogen are transferred from oxidizing substrate towards oxygen during the process of breathing; they directly participate in transformation of glucose, aldehydes, proteins, fats and other substances. Pre-sowing seed treatment of wheat with vitamins $B_{1}$ and PP improves plant growth and development, increases yields of winter wheat by $20--25 \%$, nicotinic acid significantly stimulates germination of corn seeds and sprout growth.

Antibiotic substances in whey (nisin) may antagonize phytopatogenic fungi, while immune response modifiers (angiogenin) support plant immunity.

Our previous research has shown that whey is capable of intensifying growth processes in plants; in addition, it is a source of enzymes and enzyme activators and may facilitate significant increase in activity of some enzymic preparations [4].

The goal of this work was in developing a complex environmentally friendly and zero-waste technology for production of protective and stimulating lactose-containing biological preparation on the basis of whey and medicinal plant extracts, as well as in studies of biological activity of the preparation and researching its possible application in organic agriculture. 


\section{Methods and Materials}

Technological production system of the biological preparation is a set of physicochemical processes and their hardware implementation that provide a predefined quality of the final product. Development of the process scheme for production of the biological preparation from whey provided:

- production of safe and high-quality biological preparation;

- increased economic efficiency;

- conservation of environment.

Implementation of these principles is achieved as a result of synthesizing an optimal structural diagram that includes a scientific justification for main processes and their optimal conditions.

Production of biological preparation from whey of predefined quality consists of a set of operations performed in a strictly defined order. Any changes to this system would influence the composition and quantity of the final product [12].

When composing the process diagrams, the authors took into account the results of laboratory studies, pilot-plant trials and recommendations from specialists: process engineers and agronomists. The obtained scheme is maximally close to the real production conditions.

Thorough selection of all the components and their regular control are necessary to ensure quality in production of the biological preparation.

Milky raw material used in production of the bio-preparation is fresh cheese whey and curd whey, or, alternatively, dry liophilized cheese whey. Quality control department (laboratory) of the enterprise evaluates the composition and physico-chemical characteristics of whey.

Unit 1. Raw feed acceptance, quality assessment, sorting.

Milky raw material in this production is curd whey. In addition to whey, the production uses electrochemically activated water and extracts of medicinal herbs. Activation of potable water proceeds by electrochemical method in a specially developed laboratory unit

Unit 2. Separation of fat and casein dust.

It is recommended to perform separation of whey with fat content of over $0.1 \%$ and presence of casein dust with separators Al-OXC or Al --OX2 --C at a temperature of 
$(38 \pm 2)^{\circ} \mathrm{C}$. Incoming flow of whey to the separator is regulated in such a way, that its fat content after separation never exceeds $0.1 \%$.

Unit 3. Production of plant extracts.

Pulverization of plant material is performed at a laboratory mill for 30 minutes to obtain particles sized $0.4-0.5 \mathrm{~mm}$. To extract biologically active substances from the plant material, it is overflown with the alkaline fraction of electrochemically activated water at a ratio of 1:10 between the solid and liquid phases at room temperature; extraction time is at least 12 hours in darkness at a temperature of $22^{\circ} \mathrm{C}$. The extract with fine residue is then centrifuged at $5000 \mathrm{rpm}$ for 30 minutes at room temperature.

Unit 4. Fermentation of plant extracts with whey.

To optimize the parameters of plant extract fermentation with whey, a two-factor experiment has been performed. Temperature conditions and ratio of the extracts of Saint-John's wort and common licorice to whey were selected as factors. Biological activity of the preparation determined by seed germination energy as per GOST 1203884 was used as an output parameter. The following factors have been studied: ratio between extract and whey $\left(x_{1}-1\right.$ 1:1; 1:2; 1:3; 2:1; 3:1) and temperature conditions of activation $\left(x_{2}--20,35,50{ }^{\circ} \mathrm{C}\right)$. Basing on previous research, duration of fermentation was selected as 30 minutes. Processing of experimental data resulted in an adequate regression equation:

$$
y=0.47-0.01 x_{1}+0.0003 x_{2}
$$

Analysis of this equation shows that the factors of the extract whey ratio and temperature conditions have similar effect onto growth stimulation of the final product. Thus, taking into account the data obtained, the optimal fermentation modes of plant extracts with whey were defined. Production of the biological preparation involves mixing the components in the extract: whey ratio of 1:3, and subsequent fermenting at a temperature of $35^{\circ} \mathrm{C}$ for 30 minutes.

Unit 5. Sterilization.

Sterilization of the preparation is performed with a USF--293 unit using its standard modes, thus ensuring transparency of the preparation, absence of sediment and suspended matter.

Unit 6. Bottling and packaging.

The preparation is bottled into $500 \mathrm{ml}$ flasks that are then corked with rubber stoppers and metal caps. The flasks are packaged by 10 into GOST 1230-01 compliant cardboard boxes with spacers.

Unit 7. Storage and sales. 
The preparation is stored in cold storage at a temperature of $4--8{ }^{\circ} \mathrm{C}$. Sell-by date varies from 1 month to 1 year.

\section{Results}

Qualitative and quantitative characteristics of the preparation were studied with the methods of UV and IR spectroscopy. Having preparation standardization in mind, the photometric indicators were studies at a photoelectric colorimeter FEK-56M using different filters in the wavelength range of $400-630 \mathrm{~nm}$. Qualitative and quantitative indicators of the protective-stimulating biological preparation are shown in Table 1.

TABLE 1: Qualitative and quantitative indicators of the biological preparation.

Indicator
Color
Transparency
$\mathrm{pH}$
Optic activity D400/440 nm
Growth-stimulating activity, \%

Whey-based bio-preparation
Dark beige
Transparent
6.2
0.89
$95--98$

Further research objectives were to study the influence of the produced biopreparation onto the growth-stimulating activity of plant seeds. Seeds of winter wheat var. DON-95 were selected as an object of this study into influence of the preparation. The growth-stimulating activity and sowing qualities of the seeds were determined with traditional methods and as defined in GOST 10968-6-88.

Analysis of experimental data shows that the bio-preparation has growth-stimulating activity for seeds of winter wheat. It appears as amplification of growth processes in rootlets and sprouts, which improved significantly in comparison to the control seeds. Results of applying the growth regulator to seeds of winter wheat var. Donskaia lubileinaia, gain in germination energy as compared to control seeds amounted to $9 \%$, gain in rootlet length amounted to $43 \%$, gain in sprout length amounted to $62 \%$, gain in biomass of the rootlets amounted to $26 \%$, gain in biomass of sprouts amounted to $38 \%$.

The conducted research has shown that activation of the plant extract of common licorice with whey facilitates its increased biological activity. This effect is explained by increased activation of the enzyme complex of the plant extract under the influence of biologically-active whey components. 
An important advantage of the produced preparation is its combination of growthstimulating activity with its fungicidic property, which is provided by glycyrrhizinic acid that thus determines enhancement of seed materials and biological effectiveness of protective-stimulating composition against phitopatogenic fungi at a level of 60--85 \%.

Results of assessment of protective-stimulating lactose-containing biological preparation from whey and medicinal plant extracts applied at the stage of pre-sowing seed treatment in the crop growing technology of winter wheat var. Donskaia lubileinaia at a farm in Novomaryevskaya of Shpakovsky district, Stavropol Krai point at a high level of economic efficiency that provides in comparison to control seeds, increase in yield by $530 \mathrm{~kg} /$ hectare, improved quality indicators of food-quality environmentally-friendly grain, as well as a reduction of pre-sowing seed treatment cost by a factor of 1.83 .

\section{Conclusion}

The developed new-generation biological preparation has got a name of Stimolact. From the practical point of view, it is recommended to treat seeds of winter wheat var. Don-95 with Stimolact at a rate of $2 \mathrm{l} / \mathrm{t}$ as a part of pre-sowing seed treatment.

Thus, use of lactose-containing raw materials, in particular, whey in the production technology of grain-oriented bio-preparations is aimed at increasing efficiency of organic farming in both economic and environmental aspects and is related to solution of radial problems: maintaining soil fertility, increased plant nutrition with the aim of increasing yield and environmental protection.

\section{References}

[1] Akhnovskaia, I.A., Glushich, O.V. (2014). Organic Farming is a Key to Development of Rural Districts. Theoretical \& Applied science, no. 3(11), pp. 171--174.

[2] Valko, V.P., Shchur, A.V. (2011). Peculiarities of biotechnological agriculture: Ministry of Agriculture and Foodstuffs of the Republic of Belarus. Minsk: BSATU, pp. 55--62.

[3] Dedov, A.V., Slauk, N.V., Nesmeianova, M.A. (2012). Biologization of agriculture: Current state and prospects. Annals of Voronezh State Agricultural University, no. 3, pp. 57--65.

[4] Dergunova, E.V., Shipulia, A.N., Maznitsyna, L.V., Romanenko, E.S. (2010). Biotechnological aspects of producing a complex preparation with growth stimulating and fungicid activity by fermenting plant material with whey. Scientific Life, no. 1, pp. 14-19. 
[5] Koshelev, V.M., Peshkova, A.V. (2013). Foreign experience in state support of agriculture and prospects for its application in development of domestic organic farming sector. Annals of Novosibirsk State Agricultural University, no. 2(27), pp. 164$-169$.

[6] Pashkova, E.V., Skorbina, E.A., Bezgina, lu.A., Volosova,E.V., Shipulia, A.N. (2014). Biotechnology of producing and applying protective-stimulating preparations in crop farming. Modern Problems of Science and Education, no. 2, pp. 521.

[7] Senkevich, T.-L., Ridel, K.L. (1989). Whey: Processing and Agri-Industrial Applications. Moscow: Agropromizdat, pp. 270.

[8] Khramtsov, A.G., Nesterenko, P.G. (2004). Technology of Whey Products. Moscow: DeLi print, pp. 587.

[9] Stotz, L.-P. (2012). Modern Agriculture: Translated from German. Minsk: Evolain, pp. 352

[10] Shchukin, S.V., Trufanov, A.M. (2012). Environmental Transformation of Agriculture. Transforming Traditional Farming into Organic. Moscow, pp. 196.

[11] Avdeeva, V., Zorina, E., Bezgina, J., Kolosova O. Influence of ozone on germination and germinating energy of winter wheat seeds. Engineering for Rural Development, no. 17 , pp. 545--546.

[12] Alrøe, F.H., (2006). Investigating organic agriculture in a global perspective. Environmental Justice and Global Citizenship, pp. 16--18.

[13] Esaulko, A.N, Salenko, E.A, Sigida, M.S, Korostylev, S.A., Golosnoy, E.V. (2015). Agrochemical principles of targetting winter wheat yield on leached chernozem of the Stavropol elevation. Biosciences Biotechnology Research Asia, no. 12(1), pp. 301--309.

[14] Esaulko, A.N., Grechishkina, Y.I, Sigida, M.S., Korostilev, S.A. (2016). Golosnoi The influence of fertilizer systems on the content of various forms of potassium and nutrition mode of humus. Oriental Journal of Chemistry, no. 32, iss. 6, pp. 3189-3199.

[15] Kristiansen, P., Taji, A., Reganoldt, J. (2006). Organic Agriculture. Global Perspective. New York, pp. 32--37. 